\title{
Total Organic Carbon Disappearance Kinetics for Supercritical Water Oxidation of Dimethyl Methylphospate Used as a Chemical Agent Simulant
}

\author{
Byoung Min Lee*, Bambang Veriansyah, Sung-Hyun Kim*, Jae-Duck Kim and Youn-Woo Lee ${ }^{* *,+}$ \\ Supercritical Fluid Research Laboratory, Clean Technology Research Center, \\ Korea Institute of Science and Technology (KIST), 39-1 Haweolkok-dong, Sungbuk-gu, Seoul 136-791, Korea \\ *Chemical Engineering Department, Korea University, 5-ka Anam-dong, Sungbuk-gu, Seoul 136-701, Korea \\ **School of Chemical and Biological Engineering and Institute of Chemical Process, Seoul National University (SNU), \\ San 56-1 Sillim-dong, Gwanak-gu, Seoul 151-744, Korea \\ (Received 27 December $2004 \cdot$ accepted 4 May 2005)
}

\begin{abstract}
Supercritical Water Oxidation (SCWO) has been proven to be a powerful technology to treat a wide range of wastes, but there are few references in the literature about the application of SCWO to chemical weapon agents. In this work, SCWO has been tested to treat a chemical agent stimulant, dimethyl methylphosphonate (DMMP), which is similar to the nerve agent VX and GB (Sarin) in its structure. The experiments were performed in an isothermal tubular reactor with $\mathrm{H}_{2} \mathrm{O}_{2}$ as an oxidant. The reaction temperatures ranged from 398 to $633{ }^{\circ} \mathrm{C}$ at a fixed pressure of $24 \mathrm{MPa}$. The conversion of DMMP was monitored by analyzing total organic carbon (TOC) on the liquid effluent samples. It was found that the oxidative decomposition of DMMP proceeded rapidly and a high TOC decomposition up to $99.99 \%$ was obtained within 11 seconds at $555^{\circ} \mathrm{C}$. An assumed first-order global power-law rate expression was determined with activation energy of $32.35 \pm 2.21 \mathrm{~kJ} / \mathrm{mol}$ and a pre-exponential factor of $54.63 \pm 1.45 \mathrm{~s}^{-1}$ to a $95 \%$ confidence level. By taking into account the dependence of the reaction rate on oxidant concentration, a global powerlaw rate expression was regressed from the complete set of data. The resulting activation energy was $42.00 \pm 0.41 \mathrm{~kJ} /$ $\mathrm{mol}$; the pre-exponential factor was $66.56 \pm 0.48 \mathrm{l}^{1.31} \mathrm{mmol}^{-0.31} \mathrm{~s}^{-1}$; and the reaction orders for DMMP (based on TOC) and oxidant were $0.96 \pm 0.02$ and $0.35 \pm 0.04$, respectively.
\end{abstract}

Key words: Supercritical Water Oxidation, Kinetic Reaction Rate, Chemical Agent, DMMP, Total Organic Carbon

\section{INTRODUCTION}

Under the provisions of the 1993 International Chemical Weapons Convention, all stockpiled chemical warfare agents (CWAs) are to be irreversibly destroyed. Studies of the degradation of CWAs by various technologies are underway in support of an international program for the destruction of these CWA stockpiles. The conditions of destruction for chemical weapons and munitions are shown in the Fig. 1 [Lee, 1999a, b]. Among these technologies, supercritical water oxidation (SCWO) is one of the promising technologies that can be used for the decomposition military chemical weapons.

SCWO is known to be a promising technology for treating various organic compounds including toxic organic materials like polychlorinated biphenyls (PCBs) and dioxins [Ahn et al., 1998; Anitescu and Tavlarides, 2000; Park et al., 1996, 2003; Park and Park, 2002; Tester et al., 1993; Mizuno et al., 2000; Pisharody et al., 1996]. SCWO proceeds by bringing together an oxidant, usually fed as air or oxygen, and organic compounds in the presence of water at a high temperature $\left(400-600^{\circ} \mathrm{C}\right)$ and high pressure ( $\left.25 \mathrm{MPa}\right)$. Organic compounds and oxygen can be intimately mixed in a single phase at these supercritical conditions. Thus, the rapid reactions are unhindered by inter-phase transport limitations that could occur at subcritical conditions where multiple phases could exist. Nowadays, SCWO is being applied in many pilot plants and a few commer-

To whom correspondence should be addressed.

E-mail: ywlee@snu.ac.kr

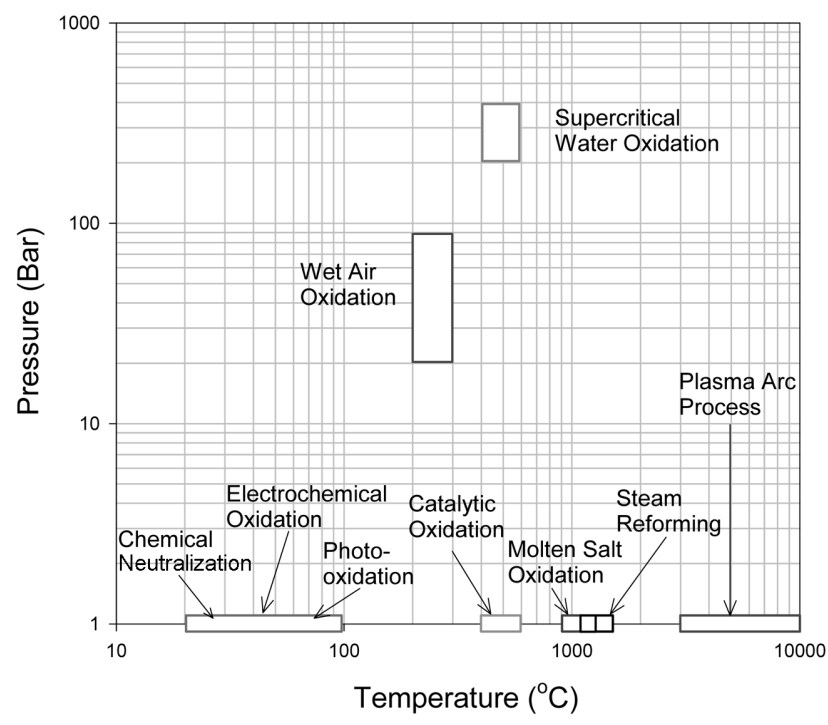

Fig. 1. Alternative technology for destruction of chemical weapons and munitions.

cial scale plants and has been successfully demonstrated for complete destruction of organic wastes efficiently [Yoo et al., 2004].

Knowledge of the kinetics of the chemical reactions that occur during SCWO is required to design and analyze SCWO reactors and processes [Oh et al., 1996]. This realization has motivated numerous previous studies of SCWO kinetics, nearly all of which have 
concentrated on the kinetics of reactant disappearance. Simply making the reactant disappear, however, by converting into a set of different organic compounds is insufficient for waste treatment by SCWO. Moreover, it is potentially dangerous if the products of incomplete oxidation are more toxic or hazardous than the starting material. It is the oxidation rate of the total organic carbon (TOC) to $\mathrm{CO}_{2}$, not the disappearance rate of the initial organic reactant itself, which is of primary applicability to the commercial SCWO process [Frisch and McBrayer, 1996]. Indeed, destruction and removal of TOC is the ultimate goal of some SCWO. Thus, the kinetics of TOC disappearance assumes particular significance.

In this paper we describe experiments of dimethyl methylphosphonate (DMMP) which was designed to identify kinetic oxidation rate in supercritical water. DMMP was chosen as a simulant for the nerve agent such as VX and GB since it is structurally similar and has physical properties that are comparable to the actual agent. DMMP has no halogen compound; therefore, there is no corrosion problem during the destruction by SCWO [Kim et al., 2000]. The chemical structure which can be described DMMP, VX and GB is shown in Fig. 2 where $R_{1}$ and $R_{2}$ are differing functional groups. For DMMP, $\mathrm{R}_{1}=\mathrm{OCH}_{3}$ and $\mathrm{R}_{2}=\mathrm{CH}_{3}$; for $\mathrm{GB}, \mathrm{R}_{1}=\mathrm{F}$ and $\mathrm{R}_{2}=\mathrm{CH}\left(\mathrm{CH}_{3}\right)_{2}$; and for $\mathrm{VX}, \mathrm{R}_{1}=\mathrm{SCH}_{2} \mathrm{CH}_{2} \mathrm{~N}\left(\mathrm{C}_{3} \mathrm{H}_{7}\right)_{2}$, and $\mathrm{R}_{2}=\mathrm{CH}_{2} \mathrm{CH}_{3}$. Select physical properties of DMMP and Agent GB are listed in Table 1 [Akzo, 2002].

\section{EXPERIMENTAL}

\section{Apparatus}

The experiments were conducted in a laboratory-scale, continuous-flow SCWO reactor system. A schematic diagram of the system for SCWO experimental apparatus is shown in Fig. 3. All wetted parts, from the high pressure pumps to the gas-liquid separator, were made of stainless steel (SS) 316 except the reactor. The reactor was

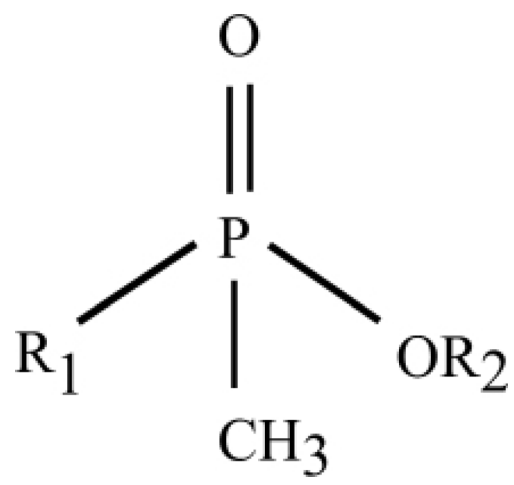

Fig. 2. Structure of chemical agent welfare.

Table 1. Physical properties of DMMP and GB

\begin{tabular}{lcc}
\hline \hline Property & DMMP & GB \\
\hline Molecular weight & 124.08 & 140.1 \\
Boiling point $\left({ }^{\circ} \mathrm{C}\right)$ & 180 & 158 \\
Melting point $\left({ }^{\circ} \mathrm{C}\right)$ & Pour point $:<-50$ & -56 \\
Density at $25{ }^{\circ} \mathrm{C}(\mathrm{g} / \mathrm{ml})$ & 1.17 & 1.09 \\
Solubility in distilled water & miscible & miscible \\
$(\mathrm{g} / 100 \mathrm{~g})$ at $25^{\circ} \mathrm{C}$ & & \\
\hline
\end{tabular}

July, 2005

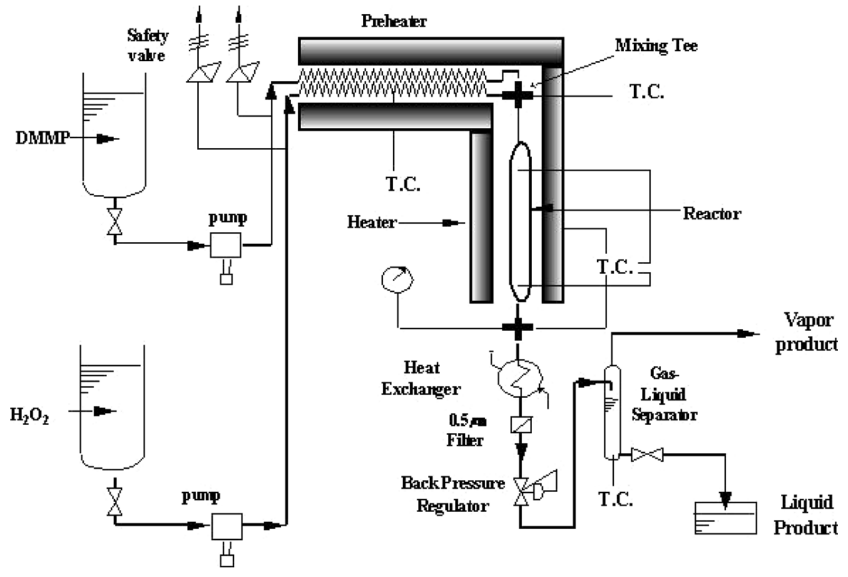

Fig. 3. Schematic diagram of the continuous-flow reactor system for SCWO.

constructed from a $280 \mathrm{~mm}$ length of $18 \mathrm{~mm}$ outside diameter (O.D.) and $9.5 \mathrm{~mm}$ inside diameter (I.D.) SS 304 tubing. The oxidant feed was prepared by dissolving hydrogen peroxide into deionized water in one feed tank. Another feed tank was loaded with DMMP solution. The feed streams were pressurized in the different lines by two high-pressure pumps (Thermo Separation Product Company) and then preheated separately. The temperature of the system was controlled by a temperature controller (Hanyoung DX 7).

DMMP feed stream was preheated within the pre-heater of $0.5 \mathrm{~m}$ 1/16-in O.D. SS 316 tubing. In order to ensure that all $\mathrm{H}_{2} \mathrm{O}_{2}$ was decomposed to give $\mathrm{H}_{2} \mathrm{O}$ and $\mathrm{O}_{2}$, the oxidant was preheated by flowing through $6 \mathrm{~m}$ coiled 1/16-in O.D. tubing. Based on the works of Croiset et al., it has been evidenced that $\mathrm{H}_{2} \mathrm{O}_{2}$ completely decomposed in the pre-heater even in those experiments carried out at high flow rate and low temperature [Croiset et al., 1997]. After preheating, two streams were mixed at the reactor inlet. The effluent of the reactor was cooled immediately by passing through a shell and tube heat exchanger to prevent additional reaction and afterwards, depressurized by using a back-pressure regulator (Tescom Co. 261721-24). The product stream was then separated into liquid and vapor phases. The liquid products were collected in a graduated cylinder, and their volumetric flow rates were determined by measuring the time interval.

\section{Materials and Analytical Methods}

DMMP (Aldrich, 97 wt $\%$ ) was the reagent used in the experiments. Hydrogen peroxide (Junsei, 35\% w/v aqueous solution) was used as an oxidant. Diluted oxidant solutions were prepared by using deionized water.

The concentrations of DMMP and liquid-phase reactor effluents were analyzed by TOC Analyzer (Shimadzu 5050), which is based on combustion and subsequent non-dispersive infrared (NDIR) gas analysis, respectively.

Destruction efficiency of TOC, X, defined as follows, was used to evaluate the extent of oxidative decomposition.

$$
\mathrm{X}=\left(1-\frac{[\mathrm{TOC}]_{f}}{[\mathrm{TOC}]_{i}}\right)
$$

where $[\mathrm{TOC}]_{i}$ is the initial TOC and $[\mathrm{TOC}]_{f}$ is the residual TOC after reaction. 


\section{RESULTS AND DISCUSSION}

Forty-one supercritical water oxidation experiments were performed in an isothermal and isobaric tubular reactor reactor. Table 2 provides the experimental conditions and a summary of the results obtained from the DMMP oxidation experiments. The oxidation reaction in this study can be represented to following stoichiometric Eq. (2).

$$
\mathrm{C}_{3} \mathrm{H}_{9} \mathrm{O}_{3} \mathrm{P}+10 \mathrm{H}_{2} \mathrm{O}_{2} \rightarrow 3 \mathrm{CO}_{2}+\mathrm{H}_{3} \mathrm{PO}_{4}+13 \mathrm{H}_{2} \mathrm{O}
$$

\section{Rate Expression for Oxidation of DMMP}

In order to develop a reliable reaction rate expression, data were taken under various conditions. The global power-law reaction rate can be described as follows:

$$
\text { Rate }=-\frac{\mathrm{d}\left[\mathrm{C}_{n}\right]}{\mathrm{dt}}=\mathrm{k}\left[\mathrm{C}_{n}\right]^{a}\left[\mathrm{H}_{2} \mathrm{O}_{2}\right]^{b}\left[\mathrm{H}_{2} \mathrm{O}\right]^{c}
$$

where $\left[\mathrm{C}_{n}\right]$ is the concentration of reactant $(\mathrm{mmol} / /) ;\left[\mathrm{H}_{2} \mathrm{O}_{2}\right]$ is the concentration of oxidant $(\mathrm{mmol} / \mathrm{l}) ;\left[\mathrm{H}_{2} \mathrm{O}\right]$ is the concentration of

\begin{tabular}{|c|c|c|c|c|c|c|}
\hline $\begin{array}{l}\text { Reaction temperature } \\
{ }^{\circ} \mathrm{C}\end{array}$ & $\begin{array}{c}\text { Reaction pressure } \\
\mathrm{MPa}\end{array}$ & $\begin{array}{l}\text { Residence time } \\
\text { sec }\end{array}$ & $\begin{array}{l}\text { TOC concentration } \\
\mathrm{mmol} / l\end{array}$ & $\begin{array}{c}\mathrm{H}_{2} \mathrm{O}_{2} \text { concentration } \\
\mathrm{mmol} / l\end{array}$ & $\begin{array}{c}\mathrm{H}_{2} \mathrm{O}_{2} \text { excess } \\
\%\end{array}$ & $\begin{array}{c}\text { TOC } \\
\text { conversion }\end{array}$ \\
\hline 398.3 & 24 & 5 & 15.81 & 104.63 & 29 & 0.58000 \\
\hline 398.4 & 24 & 5 & 31.93 & 229.92 & 26 & 0.62000 \\
\hline 398.5 & 24 & 4 & 20.10 & 177.76 & 95 & 0.53000 \\
\hline 399.3 & 24 & 8 & 23.03 & 156.01 & 30 & 0.76000 \\
\hline 399.4 & 24 & 6 & 23.97 & 224.50 & 87 & 0.71000 \\
\hline 399.6 & 24 & 5 & 20.94 & 153.20 & 43 & 0.67000 \\
\hline 399.7 & 24 & 5 & 17.69 & 110.32 & 25 & 0.58000 \\
\hline 400.2 & 24 & 5 & 21.50 & 133.02 & 24 & 0.59000 \\
\hline 400.2 & 24 & 5 & 23.48 & 150.30 & 26 & 0.63000 \\
\hline 400.2 & 24 & 5 & 23.48 & 225.45 & 90 & 0.67000 \\
\hline 400.2 & 24 & 5 & 23.48 & 300.60 & 153 & 0.69000 \\
\hline 400.2 & 24 & 8 & 3.23 & 89.14 & 200 & 0.77020 \\
\hline 400.2 & 24 & 9 & 3.23 & 89.14 & 200 & 0.84201 \\
\hline 400.2 & 24 & 11 & 3.23 & 89.14 & 200 & 0.85638 \\
\hline 400.2 & 24 & 13 & 3.23 & 89.14 & 200 & 0.87074 \\
\hline 400.4 & 24 & 7 & 31.01 & 223.89 & 26 & 0.81000 \\
\hline 401.5 & 24 & 5 & 24.10 & 246.01 & 111 & 0.65000 \\
\hline 402.0 & 24 & 5 & 23.99 & 174.28 & 51 & 0.63000 \\
\hline 420.3 & 24 & 11 & 2.65 & 73.13 & 200 & 0.88510 \\
\hline 420.3 & 24 & 12 & 2.65 & 73.13 & 200 & 0.89946 \\
\hline 420.3 & 24 & 13 & 2.65 & 73.13 & 200 & 0.91383 \\
\hline 420.3 & 24 & 15 & 2.65 & 73.13 & 200 & 0.94255 \\
\hline 440.1 & 24 & 11 & 2.34 & 64.52 & 200 & 0.91383 \\
\hline 440.1 & 24 & 12 & 2.34 & 64.52 & 200 & 0.93393 \\
\hline 440.1 & 24 & 13 & 2.34 & 64.52 & 200 & 0.95404 \\
\hline 460.5 & 24 & 10 & 2.13 & 58.74 & 200 & 0.92819 \\
\hline 460.5 & 24 & 11 & 2.13 & 58.74 & 200 & 0.94255 \\
\hline 460.5 & 24 & 12 & 2.13 & 58.74 & 200 & 0.95691 \\
\hline 480.4 & 24 & 9 & 1.97 & 54.44 & 200 & 0.94255 \\
\hline 480.4 & 24 & 10 & 1.97 & 54.44 & 200 & 0.95691 \\
\hline 480.4 & 24 & 11 & 1.97 & 54.44 & 200 & 0.97128 \\
\hline 491.9 & 24 & 13 & 5.06 & 52.35 & 200 & 0.98435 \\
\hline 493.5 & 24 & 12 & 5.04 & 104.15 & 200 & 0.98908 \\
\hline 499.5 & 24 & 12 & 7.13 & 102.26 & 200 & 0.99224 \\
\hline 499.9 & 24 & 12 & 7.13 & 51.08 & 50 & 0.98015 \\
\hline 555.5 & 24 & 11 & 4.29 & 88.62 & 500 & 0.99997 \\
\hline 556.8 & 24 & 11 & 6.17 & 88.38 & 200 & 0.99580 \\
\hline 628.7 & 24 & 9 & 5.37 & 76.99 & 200 & 0.99740 \\
\hline 628.9 & 24 & 9 & 3.72 & 38.48 & 200 & 0.99986 \\
\hline 631.5 & 24 & 9 & 3.71 & 76.63 & 500 & 0.99887 \\
\hline 633.0 & 24 & 9 & 5.33 & 38.22 & 200 & 0.99512 \\
\hline
\end{tabular}

Table 2. Summary of DMMP oxidation 
water; $\mathrm{t}$ is the reactor residence time; $\mathrm{a}, \mathrm{b}$, and $\mathrm{c}$ are the reaction orders of $\mathrm{C}_{n}, \mathrm{H}_{2} \mathrm{O}_{2}$, and $\mathrm{H}_{2} \mathrm{O}$ respectively. $\mathrm{k}$ is the rate constant, which can be expressed in Arrhenius form as follows:

$$
\mathrm{k}=\mathrm{A} \exp \left(-\mathrm{E}_{a} / \mathrm{RT}\right)
$$

where $\mathrm{A}$ and $\mathrm{E}_{a}$ are the pre-exponential factor and activation energy, respectively.

The dependence on the $\mathrm{H}_{2} \mathrm{O}$ concentration in the supercritical water oxidation reaction is not yet clearly understood. Helling and Tester found that water in Eq. (3) is not merely an inert medium for oxidation reactions [Helling and Tester, 1987]. However, some authors have assumed that water does not participate appreciably in the oxidation reaction [Krajnc and Levec, 1996; Jin et al., 2001; Gopalan and Savage, 1994]. Furthermore, negative orders for water can also be found in the literature [Oshima et al., 1998]. The possible effect of solvent on reaction rate has been extensively explained by Koo et al., concluding that it cannot be explained by phase behavior, solvation, electrostatic or transition state theory [Koo et al., 1997]. Water seems to participate in the reaction as a reactant via a multistep reaction mechanism. Since the reaction medium always consisted of more than $99 \%$ of water, its impact on the organic disappearance rate was to be avoided. Moreover, these experiments were not designed to evaluate the effect of water concentration; the reaction order for water was considered zero, so the global power-law reaction rate can be expressed as:

$$
\text { Rate }=-\frac{\mathrm{d}\left[\mathrm{C}_{n}\right]}{\mathrm{dt}}=\mathrm{k}\left[\mathrm{C}_{n}\right]^{a}\left[\mathrm{H}_{2} \mathrm{O}_{2}\right]^{b}
$$

Substituting $\mathrm{C}_{n}$ with [TOC] and rearranging the equation with respect to the TOC decomposition X defined by Eq. (1), the relationship obtained is,

$$
-\frac{\mathrm{d}[1-\mathrm{X}]}{\mathrm{dt}}=\mathrm{k}[\mathrm{TOC}]_{i}^{a-1}(1-\mathrm{X})^{a}\left[\mathrm{H}_{2} \mathrm{O}_{2}\right]^{b}
$$

In Eq. (6) if reaction order of TOC is assumed to be first order and the change in oxidant concentration throughout the reaction is assumed insignificant, regardless of the order of reaction with respect to the oxidizer, an integral equation will become,

$$
\ln (1-X)=-k t
$$

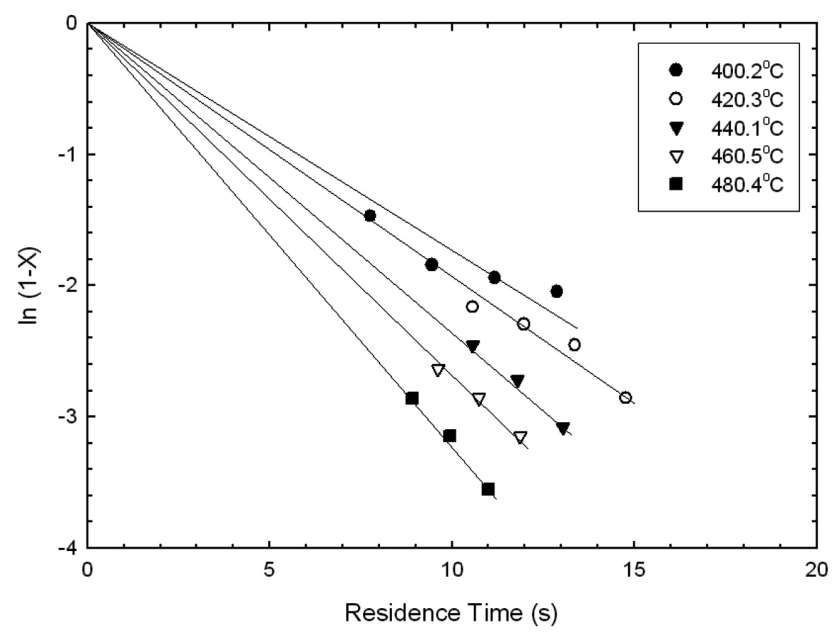

Fig. 4. Plot of $\ln (1-X)$ against residence time for DMMP in SCWO.

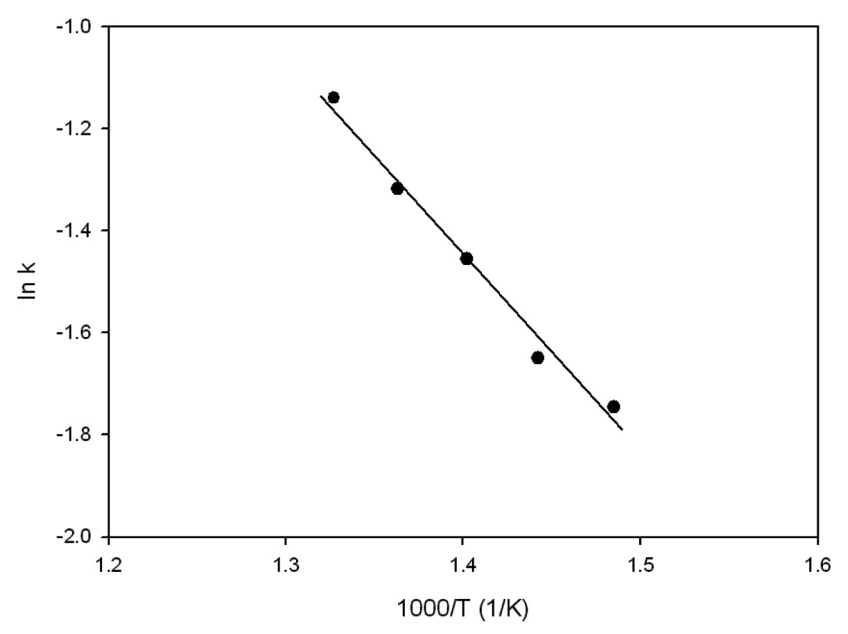

Fig. 5. Assumed first order Arrhenius plot for DMMP in SCWO.

A plot of $\ln (1-X)$ against the residence time (for each temperature) is shown in Fig. 4. The negative slope of each linear fit gave the rate constant, $\mathrm{k}$. The Arrhenius plot, shown in Fig. 5, provides estimates of global activation energy of $32.35 \pm 2.21 \mathrm{~kJ} / \mathrm{mol}$ and a pre-exponential factor of $54.63 \pm 1.45 \mathrm{~s}^{-1}$ to a $95 \%$ confidence level. The resulting first-order rate expression for the oxidation of DMMP is as follows:

$$
-\frac{\mathrm{d}[\mathrm{TOC}]}{\mathrm{dt}}=54.63 \pm 1.45 \exp \left(\frac{-32.35 \pm 2.21}{\mathrm{RT}}\right)[\mathrm{TOC}]
$$

\section{Effect of Oxidant Concentration}

In order to investigate the effect of the concentrations of oxidant on the decomposition rate of TOC, three experiments were conducted at a temperature $400 \pm 1{ }^{\circ} \mathrm{C}$, a pressure of $24 \mathrm{MPa}$, and residence times of 5 seconds. The TOC concentration at the reactor was fixed at $23.48 \mathrm{mmol} / \mathrm{l}$. In these experiments, the oxidant excess was varied from $26 \%$ to $153 \%$. As can be seen in Fig. 6 the TOC conversions are enhanced by increasing oxidant concentration. This is an indication of the fact that the global reaction order for oxidant is greater than zero.

In this study, the rate equation is assumed to depend on the tem-

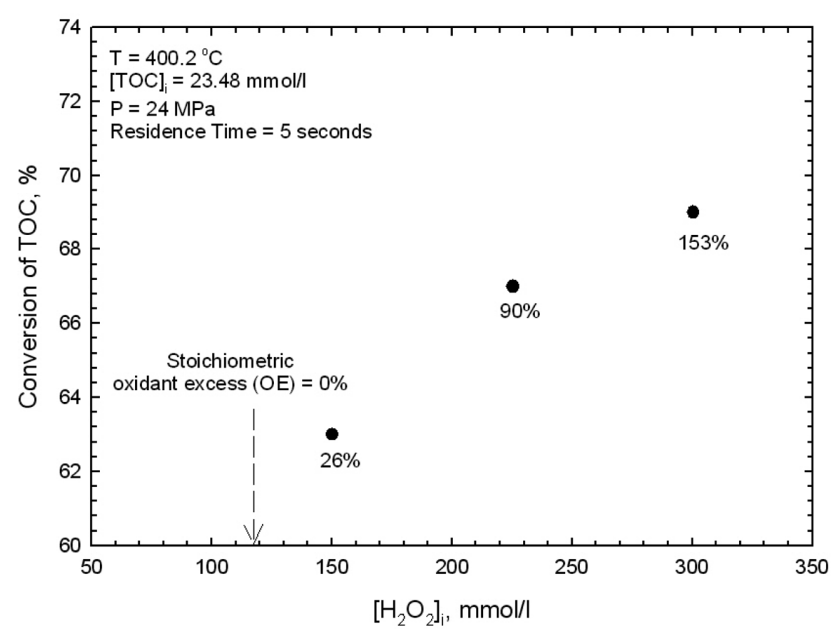

Fig. 6. Effect of oxidant feed concentration on TOC conversion. 
perature, the TOC and $\mathrm{H}_{2} \mathrm{O}_{2}$ concentration. Since all of experiments were performed at very short contact time, between 4 and 15 seconds, the method of initial rates can be used for all data [Fogler, 2000].

If the method of initial rate is applied to Eq. (6) with the initial condition $\mathrm{X}=0$ at reaction time $\mathrm{t}=0$, it can be solved analytically to provide Eq. (9) as the relationship between the TOC removal efficiency and the experiment variables.

$$
\mathrm{X}=1-\left[1-(1-\mathrm{a}) \mathrm{kt}[\mathrm{TOC}]_{i}^{a-1}\left[\mathrm{H}_{2} \mathrm{O}_{2}\right]_{i}^{b}\right]^{\frac{1}{(1-a)}} \text { for } \mathrm{a} \neq 1
$$

A non-linear regression analysis is used to fit the rate of reaction, and estimation of the parameter values was made in order to predict the rate of reaction. Confidence values can be reached by minimizing the sum of the squares differences of the experimental and the predicted conversion $\mathrm{s}^{2}=\sum_{i}^{N_{\text {exp }}}\left(\mathrm{X}_{\text {exp }}-\mathrm{X}_{\text {pred }}\right)^{2}$ for all data points [Fogler, 2000].

These 41 data led to reaction orders of $\mathrm{a}=0.96 \pm 0.02$ for TOC, and $b=0.35 \pm 0.04$ for oxidant, respectively. The values of the Arrhenius parameters, $\mathrm{A}$ and $\mathrm{E}_{a}$ are $66.56 \pm 0.48 l^{1.31} \mathrm{mmol}^{-0.31} \mathrm{~s}^{-1}$ and $42.00 \pm$ $0.41 \mathrm{~kJ} / \mathrm{mol}$, respectively. The uncertainties reported here are the $95 \%$ confidence intervals.

$$
\begin{aligned}
-\frac{\mathrm{d}[\mathrm{TOC}]}{\mathrm{dt}}= & 66.56( \pm 0.48) \\
& \exp \left(\frac{-42.00 \pm 0.41}{\mathrm{RT}}\right)[\mathrm{TOC}]^{0.96 \pm 0.02}\left[\mathrm{H}_{2} \mathrm{O}_{2}\right]^{0.35 \pm 0.04}
\end{aligned}
$$

Fig. 7 shows a parity plot of the rate predicted from the global rate law by using the parameters from experiments data in Eq. (9) against the rate obtained experimentally. A perfect fit of the model to the data would result in all the points lying on the $45^{\circ}$ line. Our model fits the experimental data reasonably well over the range of conversion.

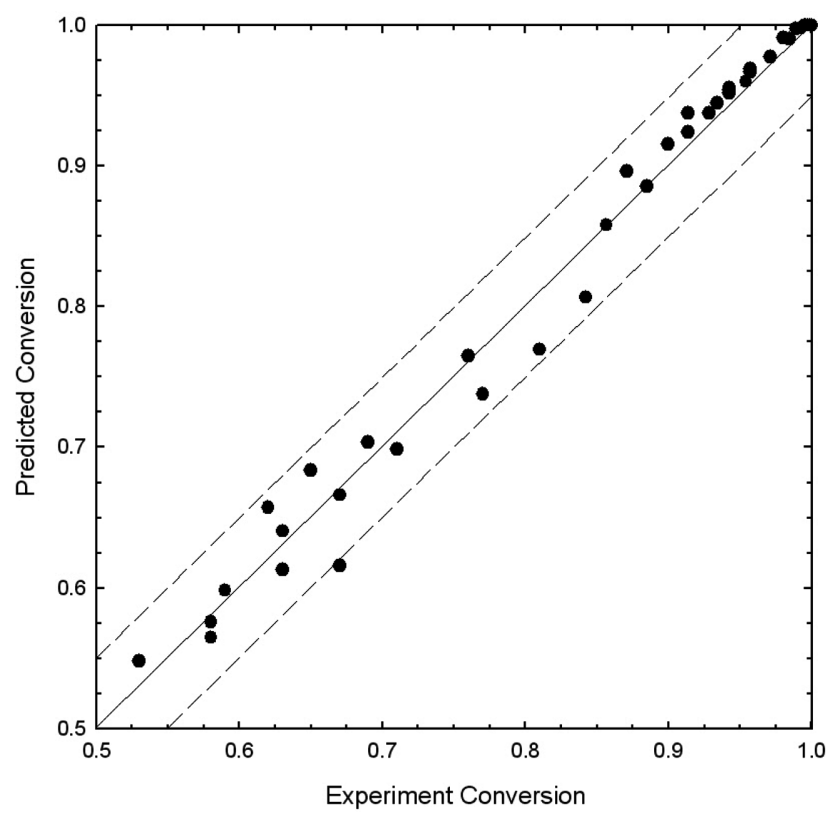

Fig. 7. Parity plot for power-law rate equation for TOC conversion.

\section{CONCLUSION}

Decomposition of DMMP in supercritical water was studied in a continuous flow tubular reactor. It was found that TOC conversion greater than $99.99 \%$ can be obtained within 11 seconds at temperature of $555.5^{\circ} \mathrm{C}$. Assuming the oxidation reaction was first order in wastewater and zero order in oxidant, the calculated activation energy was $32.35 \pm 2.21 \mathrm{~kJ} / \mathrm{mol}$ and the pre-exponential factor was $54.63 \pm 1.45 \mathrm{~s}^{-1}$ at a $95 \%$ confidence level.

A series of experiments was carried out for the examination of the oxidant concentration dependence. All oxidation data including the specific oxygen dependence experiments were used to fit the rate of reaction in a non-linear regression analysis, assuming a zeroorder dependence on water concentration. Parameter values were determined to be $66.56 \pm 0.48 l^{1.31} \mathrm{mmol}^{-0.31} \mathrm{~s}^{-1}$ for the pre-exponential factor, $42.00 \pm 0.41 \mathrm{~kJ} / \mathrm{mol}$ for the activation energy, and for the reaction order, $0.96 \pm 0.02$ for TOC, and $0.35 \pm 0.04$ for oxidant. DMMP could be completely destroyed at supercritical temperature and pressure with sufficient amount of oxidant.

\section{ACKNOWLEDGMENTS}

This work has been supported by the National Research Laboratory Program for Supercritical Fluids, and the authors would like to thank to the Ministry of Science and Technology, Korea.

\section{REFERENCES}

Akzo Nobel Function Chemical bv, "MSDS of Fyrol DMMP,' Safety Data Sheet, 2002, http://www.phosphoruschemicals.com/pdf/fyrol\% 20dmmp\%20msds.pdf

Ahn, S. H., Joung, S. N., Yoo, K.-P., Noh, M. J., Han, J. H. and Han, S. H., "Oxidation Characteristics of Phthalic and Adipic Acids by Supercritical Water,' Korean J. Chem. Eng., 15, 390 (1998).

Anitescu, G and Tavlarides, L. L., "Oxidation of Aroclor 1248 in Supercritical Water: A Global Kinetic Study,' Ind. Eng. Chem. Res., 39, 583 (2000).

Croiset, E., Rice, S. F. and Hanush, R. G, 'Hydrogen Peroxide Decomposition in Supercritical Water,' AIChE J., 43(9), 2343 (1997).

Fogler, H. S., Elements of Chemical Reaction Engineering, Prentice Hall International (UK) Limited, London (2000).

Frisch, M. and McBrayer, R., SCWO Commercialization: Integrating Bench, Pilot, and Commercial-scale Research, presented at the Annual Meeting of the American Institute of Chemical Engineers, Chicago, IL, Paper 128a, Nov. (1996).

Gopalan, S. and Savage, P. E., "Reaction Mechanism for Phenol Oxidation in Supercritical Water,' J. Phys. Chem., 98, 12646 (1994).

Helling, R. K. and Tester, J. W., "Oxidation Kinetics of Carbon Monoxide in Supercritical Water,' Energy Fuels, 1, 417 (1987).

Jin, F. M., Kishita, A., Moriya, T. and Enomoto, H., 'Kinetics of Oxidation of Food Wastes with $\mathrm{H}_{2} \mathrm{O}_{2}$ in Supercritical Water,' J. Supercritic. Fluids, 19, 251 (2001).

Kim, Y. S., Mitton, D. B. and Latanision, R. M., "Corrosion Resistance of Stainless Steels in Choride Containing Supercritical Water Oxidation System,' Korean J. Chem. Eng., 17, 58 (2000).

Koo, M., Lee, W. K. and Lee, C. H., 'New Reactor System for Supercritical Water Oxidation and its Application on Phenol Application," 
Chem. Eng. Sci., 52(7), 1201 (1997).

Krajnc, M. and Levec, J., "On the Kinetics of Phenol Oxidation in Supercritical Water,' AIChE J., 42(7), 1977 (1996).

Lee, J. C., "Chemical Weapons Destruction Technology (I)," J. Korea Solid Waste Engineering Society. 16, 205 (1999).

Lee, J. C., "Chemical Weapons Destruction Technology (II),' J. Korea Solid Waste Engineering Society, 16, 205 (1999).

Mizuno, T., Goto, M., Kodama, A. and Hirose, T., "Supercritical Water Oxidation of a Model Municipal Solid Waste,' Ind. Eng. Chem. Res., 39, 2807 (2000).

Oh, C. H., Kochan, R. J., Charlton, T. R. and Bourhis, A. L., "Thermal Hydraulic Modeling of Supercritical Water Oxidation of Ethanol,' Energy Fuels, 10, 326 (1996).

Oshima, Y., Hori, K., Toda, M. and Chommanad, T., 'Phenol Oxidation Kinetics in Supercritical Water,' J. Supercrit. Fluids, 13, 241 (1998).

Park, J. H. and Park, S. D., "Kinetics of Cellobiose Decomposition Under Subcritical and Supercritical Water in Continuous Flow System,"
Korean J. Chem. Eng., 19, 960 (2002).

Park, S.-W., Yoon, J.-H. and Lee, H., "Destruction of CFC113 in Supercritical and Subcritical Water,' Korean. J. Chem. Eng., 13, 640 (1996).

Park, T. J., Lim, J. S., Lee, Y.-W. and Kim, S. H., "Catalytic Supercritical Water Oxidation of Wastewater from Terephthalic Acid Manufacturing Process,' J. Supercritical Fluid, 26(3), 201 (2003).

Pisharody, S. A., Tester, J. W. and Abraham, M. A., "Supercritical Water Oxidation of Solid Particulates,' Ind. Eng. Chem. Res., 35, 4471 (1996).

Tester, J. W., Holgate, H. R., Armellini, F. J., Webley, P. A., Killilea, W. R., Hong, G T. and Barner, H. E., "Supercritical Water Oxidation Technology,' ACS Symposium Series, 513, 35 (1993).

Yoo, K. P., Lim, J. S., Kim, S. Y., Han, J. H. and Lee, Y.-W., Recent Commercial Applications of SFE, SFD, SCWO, SCORR and Nano-Materials in Korea, presented at $11^{\text {th }}$ International Symposium \& Exhibit on Supercritical Fluid Chromatography, Extraction, and Processing, Pittsburgh, USA, August (2004). 